\title{
Molecular tailoring to improve polypyrrole hydrogels' stiffness and electrochemical energy storage capacity
}

\author{
Evelyn Chalmers, Yi Li, Xuqing Liu (ه) \\ School of Materials, The University of Manchester, Manchester M13 9PL, UK
}

(C) The Author(s) 2019. This article is published with open access at link.springer.com and journal.hep.com.cn 2019

\begin{abstract}
This research looks at ways of tailoring and improving the stiffness of polypyrrole hydrogels for use as flexible supercapacitor electrodes. Molecules providing additional cross-linking between polypyrrole chains are added post-polymerisation but before gelation, and are found to increase gel stiffness by up to $600 \%$, with the degree of change dependent on reactant type and proportion. It was also found that addition of phytic acid led to an increase in pseudocapacitive behaviour of the hydrogel, and thus a maximum specific capacitance of $217.07 \mathrm{~F} \cdot \mathrm{g}^{-1}$ could be achieved. This is an increase of $140 \%$ compared to pristine polypyrrole hydrogels produced by this method.
\end{abstract}

Keywords supercapacitor, polypyrrole, hydrogel, strengthening, electrochemical

\section{Introduction}

The past decade has seen the rise of supercapacitors as a new avenue into energy storage technology, particularly in combination with personalised energy harvesting. Supercapacitors combine the benefits of batteries and capacitors; in particular their high energy storage and fast charge/ discharge rate. They present a new manner of incorporating energy storage into textiles and wearable devices as they can be produced in wider range of architectures, such as fibres, and with a wider range of materials - most notably conducting polymers $[1,2]$. In addition to the electrical double layer capacitance (EDLC) arising from the use of high-surface area electrodes, use of conducting polymers provide additional charge storage through their ability to undergo reversible reduction and oxidation

Received September 27, 2018; accepted January 21, 2019

E-mail: xuqing.liu@manchester.ac.uk reactions. This is known as pseudocapacitance, and can be combined with EDLC to further increase the charge storage abilities of the supercapacitor.

Current supercapacitors often employ conducting polymers either as films or with an engineered microstructure to provide a high surface area and flexibility. This helps improve EDLC and also increase access of electrolyte for pseudocapacitive charge transfer, whilst maintaining the low density and ease of processability of polymers compared to metals [3]. Increasingly, however, research is taking inspiration from biological materials to form conducting polymer hydrogels. These are networks of water-insoluble polymers which are cross-linked and swollen by water. Hydrogels can provide both a high electrode surface area and improved elasticity, as deformation occurs by the movement of water in hydrogel pores rather than movement of conducting polymer chains. Elasticity in particular is needed for supercapacitor incorporation in comfortable, wearable sports and medical monitors, and to minimise the swelling which occurs during charging of the polymer electrodes and has been shown to lead to early device failure due to structural degradation [4].

Polypyrrole is a commonly-used conducting polymer for supercapacitor electrodes, as it can achieve conductivities of $42 \mathrm{~S} \cdot \mathrm{cm}^{-1}$ in nanotube-hydrogel form, is capable of redox reactions and hydrogen bonding, and can be processed in aqueous solution at low temperatures [5-8]. However, charging-induced swelling and degradation of these polypyrrole hydrogels, which arises due to their low stiffness and low tensile strength, still presents a problem. Improvement of these characteristics is required for integration of polypyrrole-based supercapacitors into clothing: In particular sports monitoring clothing such as Lycra $^{\mathrm{TM}}$, which demonstrates a recoverable extension of over $600 \%$ and an ultimate tensile strength of $8 \mathrm{MPa}$ [9]. Polypyrrole hydrogels can be produced via chemical oxidative polymerisation, often with other molecules 
added pre-polymerisation to provide cross-linking effects. When performed in aqueous solution, gel networks or dispersions of polypyrrole nanospheres are formed, depending on whether a cross-linking molecule is incorporated. During polymerisation, polypyrrole has a tendency to branch (and therefore form cross-links) via polymerisation occurring at the $\beta$-carbon atoms. These carbon atoms are not involved in the conjugated bonding of the polypyrrole and therefore this branching does not contribute to polypyrrole's conductivity. Branching also decreases the average molecular weight of the polymer and leads to an increase in detrimental swelling behaviour. One way to overcome this is to polymerise close to $0^{\circ} \mathrm{C}$, which has been found to promote long-chain growth $[7,10,11]$.

The most-common cross-linking addition is phytic acid. This planar molecule with six phosphate groups can form hydrogen bonds to multiple polypyrrole chains and thus act as cross-link sites. Research has shown that adding phytic acid to solutions of pyrrole prior to polymerisation can alter the morphology and mechanical properties of polypyrrole gels, and these properties can be tailored by changing the molar proportions of the reactants $[12,13]$. These gels were simultaneously oxidised and doped using ferric chloride or ammonium persulphate, and relied solely on phytic acid to provide cross-linking and thus create a polypyrrole hydrogel. However, addition of these molecules pre-polymerisation may disrupt the monomer's electron distribution and polymerisation mechanism, and thus affect the hydrogel's conductivity. Work by Rajesh's group [14] has also demonstrated the anionic doping ability of phytic acid via its phosphate groups. However, the large size of the dopant phytic acid molecule may lead to a decrease in the maximum doping density (and thus conductivity) achievable for polypyrrole due to steric hindrance effects in comparison to smaller dopant anions. Other additives which could provide additional cross-links through hydrogen bonding have not been examined in as much detail. These include molecules such as tannic acid; a planar polyphenol which is both naturally occurring and water soluble. Its solubility and easily-broken hydrogen bonds may enable self-healing properties of polypyrrole hydrogels, which has not yet been observed.

Incorporation of stiff phases such as graphene (which can contribute to the EDLC of the electrode) can provide cross-linking through both hydrogen bonding (via $-\mathrm{OH}$ groups on graphene oxide) and $\pi-\pi$ stacking $[15,16]$. Incorporation is performed either through infiltration of the pyrrole into a graphene hydrogel structure followed by polymerisation, or simultaneous formation of both gels. However, this route is currently limited by both its cost and ease of processing. In contrast, Lu's paper in 2014 demonstrated that cohesive polypyrrole hydrogels could be formed from just two reactants without an additional cross-linking molecule - a much more scalable process [17]. They used a stoichiometric deficiency of ferric nitrate oxidant to enable a secondary stage of $\mathrm{Fe}^{3+}$-initiated network growth, akin to sintering in a ceramic green compact, which acted to form an elastic gel network. Additionally, the anions provided by the ferric salt are incorporated into polymer as the dopant, removing the need for additional reactants. They found that the more stable $\left[\mathrm{NO}_{3}\right]^{-}$anion was required to regenerate the iron catalyst (aided by $\mathrm{H}^{+}$ions produced during polymerisation) to initiate this secondary growth - other common oxidants such as $\mathrm{FeCl}_{3}$ do not have this property and therefore form dispersions of polypyrrole rather than gels [10]. At the time of writing, no reports have been produced regarding the effect of changing crosslink density, or the electrochemical properties of these two-reactant polypyrrole hydrogels.

Control of gel stiffness can also be achieved through additional cross-linking by multivalent ions [18-20], which form chelate complexes with the doped polypyrrole. Most notably, this has been demonstrated with $\mathrm{Fe}^{3+}$ cations in poly(3,4-ethylenedioxythiophene)/poly(styrenesulfonate) [21]. However, this method of cross-linking with $\mathrm{Fe}^{3+}$ succeeded because of the negatively-charged sulfonic groups of the poly(styrene sulfonate). Polypyrrole can only stably be $p$-doped, so electrostatic repulsion may mean that cationic chelation cannot be achieved in the same way [22]. Instead, molecules of copper phthalocyanine$3,4^{\prime}, 4$ ",4"'-tetrasulfonic acid tetrasodium salt have been shown to cross-link polypyrrole through electrostatic interaction between sulfonate groups and $p$-doped polypyrrole; producing self-assembled hydrogels of polypyrrole nanorods which were highly conductive. However, no testing of the gels' mechanical properties was performed [23].

In this paper, we examine the effect of additional molecules, added post-polymerisation, on the mechanical and electrochemical behaviour of polypyrrole hydrogels. Firstly, the porosity of the gels is tailored by use of a tworeactant, one-pot creation method developed by Lu's group [17] using aqueous solutions of ferric salts, with a stoichiometric deficiency of initiating $\mathrm{Fe}^{3+}$ to enable strengthening of the hydrogel network via a secondary step of polypyrrole growth. Both ferric sulphate and ferric nitrate are used to provide a comparison between anionic dopant charge and its effect on gel morphology and electrochemical behaviour. Additional cross-linking molecules (primarily phytic acid and tannic acid) are then added to provide cross-linking via inter- and intra-chain hydrogen bonding. We also look at adding more $\mathrm{Fe}^{3+}$ alongside additional singly- or doubly-charged anionic dopant after polymerisation has occurred. Iron(III) ions act as the initiator for polymerisation, so when added to stoichiometrically-deficient polypyrrole gels will grow short-chain polypyrrole within the existing network to act as crosslinks. The doubly-charged sulfonate anion is also expected to act as a simultaneous dopant and cross-linker. These additives are expected to increase the cross-link density of the polypyrrole hydrogel, and their impact is assessed by 
looking at morphological, electrochemical, and mechanical properties of the hydrogels.

\section{Materials and methods}

Polypyrrole hydrogels were first created via a two-reactant, one-pot process. Pyrrole (obtained from Sigma Aldrich, $>$ 97\% purity) was dissolved in a 1:1 by weight solvent of water:ethanol, to achieve a concentration of $0.209 \mathrm{~mol}$ $\cdot \mathrm{L}^{-1}$. Lower concentrations were found to produce dispersions of polypyrrole when polymerised, but did not gelate due to lack of sphere impingement. Aqueous solutions of ferric nitrate (nonahydrate) and ferric sulphate (both Sigma Aldrich, 97\%) were made at concentrations of $0.5 \mathrm{~mol} \cdot \mathrm{L}^{-1}$. We found that resultant solvent ratios of $1: 1$ and 3:1 water; EtOH produced identical gel morphologies. Polymerisation of the gels was then carried out in an ice bath at $0^{\circ} \mathrm{C}$, by mixing volumes of the two reactants at $1: 1$ molar ratios of pyrrole:ferric salt, to create a mixture totalling $4 \mathrm{~mL}$. It has been found in our previous unpublished research that a controllable gel porosity and nanosphere size can be achieved through varying the molar proportions of pyrrole and ferric salt. However, a molar ratio of $1: 1$, which is stoichiometrically deficient of ferric salt, leads to secondary growth of the polypyrrole network and thus produced the most cohesive hydrogels.

The additional reactants were added post mixing but before gelation could occur (which was seen to take in excess of $5 \mathrm{~min}$ for the concentrations used here [17]. Phytic acid, ferric nitrate, ferric sulphate, potassium hydroxide, sodium hydrogen carbonate (all Sigma Aldrich), and the ionic liquid 1-hexyl-3-methylimidazolium hexafluorophosphate (P106) (produced by this research group) were dissolved in water to form solutions at $1 \mathrm{mmol} \cdot \mathrm{L}^{-1}$ concentration. Tannic acid was dissolved in water at a lower concentration of $0.1 \mathrm{mmol} \cdot \mathrm{L}^{-1}$ due to its high molecular weight leading to a viscous solution at higher concentrations, which could not be infiltrated into the gel. These reactants were added to separate mixtures of polypyrrole created with ferric nitrate, which was found to produce the most elastic hydrogels [23], at ratios of 1 millimole of reactant: 1 mole pyrrole. As a comparison, excess ferric sulphate and phytic acid were added to gels made with 1:1 ferric sulphate:pyrrole. The gels were then aged at room temperature for $30 \mathrm{~d}$ to promote secondary polymerisation and network growth. Sealed glass containers were used to prevent water evaporation which would lead to pore collapse and a decrease in charge storage capacity [24]. After $30 \mathrm{~d}$, the gels were washed with deionised water until $\mathrm{pH}$ neutral to remove any excess $\mathrm{Fe}^{3}$ ${ }^{+}$, unreacted pyrrole, $\mathrm{H}^{+}$ions (produced during polymerisation), and unbonded cross-linking chemicals.

\section{Results and discussion}

\subsection{Characterisation}

SEM imaging was performed on freeze-dried samples using a Sirion FEG-SEM microscope. Figure 1 shows the

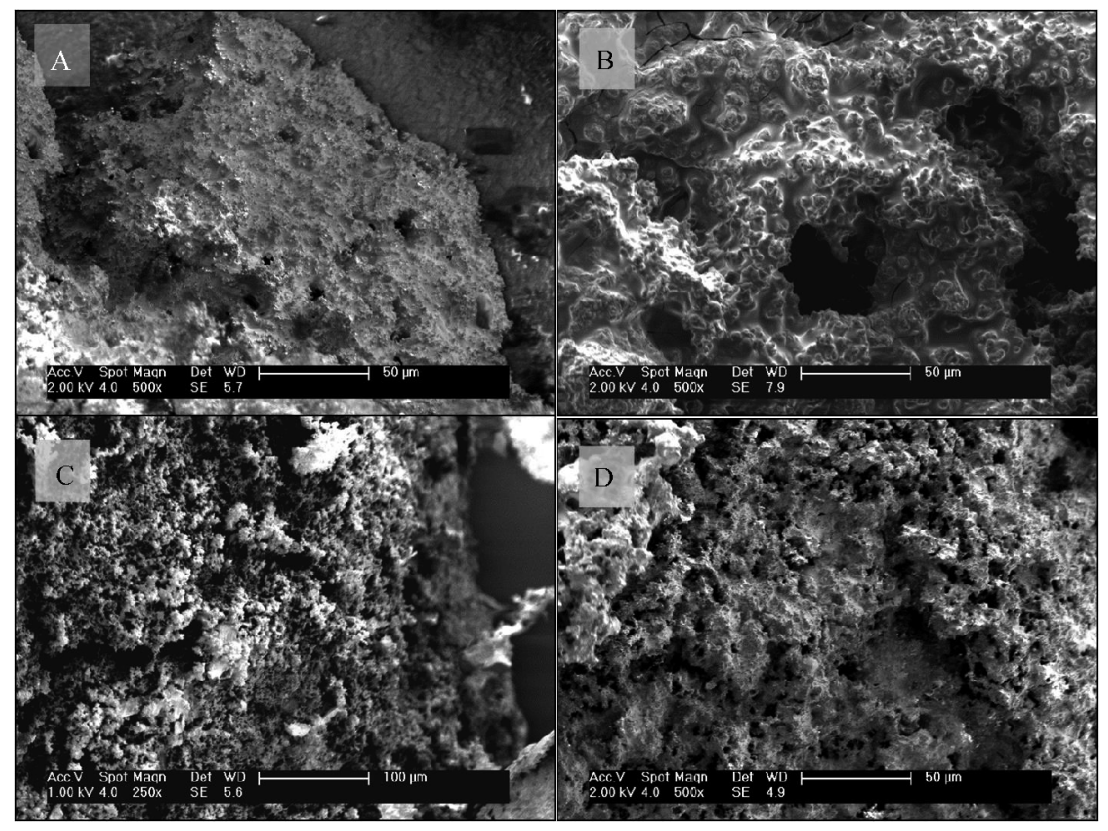

Fig. 1 SEM images taken of polypyrrole hydrogels made with a $1: 1$ molar ratio of pyrrole: $\mathrm{Fe}\left(\mathrm{NO}_{3}\right)_{3} \cdot(\mathrm{A})$ with $1 \mathrm{mmol} \cdot \mathrm{L}^{-1} \mathrm{Fe}\left(\mathrm{NO}_{3}\right)_{3}$ added, (B) with $1 \mathrm{mmol} \cdot \mathrm{L}^{-1}$ phytic acid added, (C) with $1 \mathrm{mmol} \cdot \mathrm{L}^{-1} \mathrm{KOH}$ added, (D) with $1 \mathrm{mmol} \cdot \mathrm{L}^{-1} \mathrm{NaHCO}_{3}$ added 
effect of adding excess reactants to hydrogels made of 1:1 molar ratio pyrrole:ferric nitrate (which were typically the gels with the highest elasticity due to increased $\mathrm{Fe}^{3+}$ concentration and secondary polypyrrole growth). Figure 2 shows the effect of adding excess ferric sulphate and phytic acid on the morphology of hydrogels made with a 1:1 molar ratio of pyrrole:ferric sulphate. It can be seen that adding excess $\mathrm{Fe}\left(\mathrm{NO}_{3}\right)_{3}$ led to polypyrrole formation in the voids of the pre-existing hydrogel, resulting in an extensive decrease in surface area and loss of nanosphere definition. However, addition of excess $\mathrm{Fe}_{2}\left(\mathrm{SO}_{4}\right)_{3}$ to polypyrrole hydrogels formed well-dispersed beads of secondary-made polypyrrole within the hydrogel structure without a loss in surface area. However, these interconnection points may help improve the network strength. Addition of phytic acid to either hydrogel resulted in a loss of surface area, as seen in Figs. 1(B) and 2(B). Upon addition, a gelatinous white substance was observed to form in the solution, which may be due to a reaction of phytic acid with excess sulphate anions not incorporated into the polypyrrole. These additions formed stiff gels with an absence of any microstructure, aside from a few large spheres which immersed in dense polypyrrole. Addition of $\mathrm{KOH}$ and $\mathrm{NaHCO}_{3}$ resulted in much less agglomeration and loss of surface area. This is likely because $\mathrm{K}^{+}$and $\mathrm{Na}^{+}$ are not sufficiently electrophilic to induce secondary polymerisation of pyrrole and thus grow the network. It was also seen that adding $\mathrm{NaHCO}_{3}$ initially produced bubbles of $\mathrm{CO}_{2}$ as it reacted with the $\mathrm{H}^{+}$ions produced by pyrrole polymerisation; these bubbles may help to increase the porosity of the gel. They also resulted in neutralisation of the polypyrrole, but after ageing it was seen that the $\mathrm{pH}$ returned to $\mathrm{pH}$ 2. This is an indication that secondary polymerisation of the pyrrole still occurs, which was also indicated by the presence of some interconnectivity observed when $\mathrm{NaHCO}_{3}$ was used - the $\left[\mathrm{CO}_{3}\right]^{2-}$ may be acting to 'regenerate' the $\mathrm{Fe}^{3+}$ and allow it to further initiate the formation of radical cations of pyrrole, and thus some secondary polymerisation of pyrrole occurs [17].

Fourier transform infrared spectroscopy (FTIR) measurements were performed with Nicolet 5700 spectrometer in absorbance mode, and the spectra are shown in Fig. 3. All excess reactant solutions were made in deionised water, so the peaks corresponding to ethanol (used to increase the concentration of pyrrole solution before polymerisation) decrease in intensity once the secondary reagent is added. Few changes were seen in the spectra when phytic acid was added to polypyrrole hydrogels made with ferric nitrate, as seen in Fig. 3(b). However, the peak representing the outof-plane $\mathrm{P}-\mathrm{O}-\mathrm{C}$ bonding of the phytic acid molecules shifts up from 1040 to $1056 \mathrm{~cm}^{-1}$, indicating an increase in planar confinement of the molecules. However, addition of phytic acid to polypyrrole hydrogels made with ferric sulphate (Fig. 3(e)) caused the peak corresponding to the $\mathrm{C}-\mathrm{O}$ stretch of the phytic acid decreases from 1124 to $1091 \mathrm{~cm}^{-1}$, i.e., the connection of the phosphate group to the central hexane decreases in strength. Additionally, the peak corresponding to the $\mathrm{P}=\mathrm{O}$ bonds increased from 1160 to $1195 \mathrm{~cm}^{-1}$, indicating tighter hydrogen bonding to the polypyrrole. The stretches of the phosphorus-hydroxyl groups are also lost, most likely due to immobilisation of the groups due to strong hydrogen bonding to the polypyrrole.

Adding $\mathrm{KOH}$ to hydrogels made with ferric nitrate introduced three new peaks as seen in Fig. 3(c); the first at $964 \mathrm{~cm}^{-1}$, a broad peak from 1172 to $1213 \mathrm{~cm}^{-1}$, and at $1533 \mathrm{~cm}^{-1}$. The broad shoulder most likely corresponds to a new $\mathrm{C}-\mathrm{O}$ bond, indicating ring opening of the polypyrrole due to the alkaline environment. This is not ideal as ring-opening destroys the bond conjugation and thus prevents charge movement along the chain $[25,26]$. The peak at $964 \mathrm{~cm}^{-1}$ is due to a trans-sp ${ }^{2}$ stretch, again arising from ring-opening of the polypyrrole, whilst the peak at $1533 \mathrm{~cm}^{-1}$ is due to the $\left[\mathrm{NO}_{3}\right]^{-}$anion, indicating that the potassium hydroxide draws some of the anionic dopant out from the polypyrrole. Adding $\mathrm{NaHCO}_{3}$ to polypyrrole gels made with ferric nitrate produced four new peaks, as shown in Fig. 3(d). Again, a trans-sp ${ }^{2}$ stretch was seen at $962 \mathrm{~cm}^{-1}$; a broad/double peak at 1216 and $1230 \mathrm{~cm}^{-1}$ (again corresponding to a $\mathrm{C}-\mathrm{O}$ stretch from ring opening - it is likely that the broad peak seen in Fig. 3(c) is an unresolved double peak); a peak at $1542 \mathrm{~cm}^{-1}$

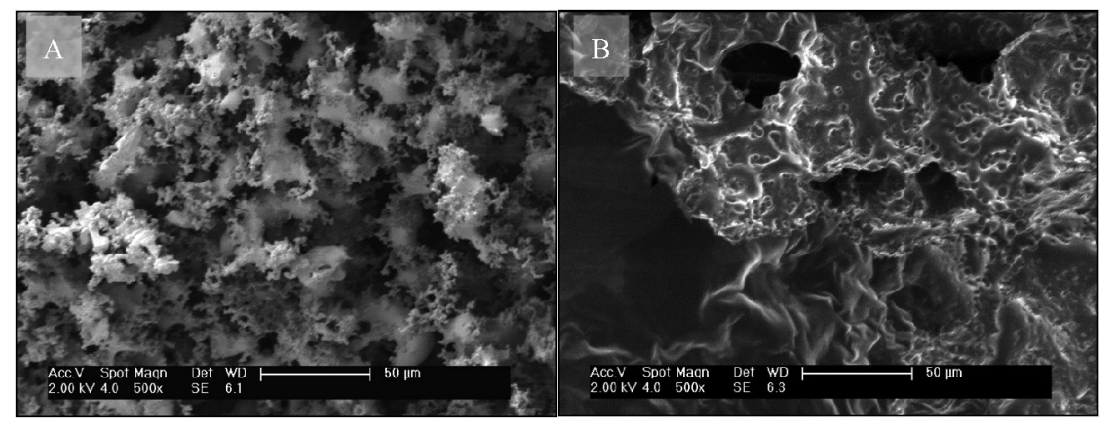

Fig. 2 SEM images taken of polypyrrole hydrogels made with a $1: 1$ molar ratio of pyrrole: $\mathrm{Fe}_{2}\left(\mathrm{SO}_{4}\right)_{3}$. (A) with $1 \mathrm{~mol} \cdot \mathrm{L}^{-1} \mathrm{Fe}_{2}\left(\mathrm{SO}_{4}\right)_{3}$ added, (B) with $1 \mathrm{~mol} \cdot \mathrm{L}^{-1}$ phytic acid added 

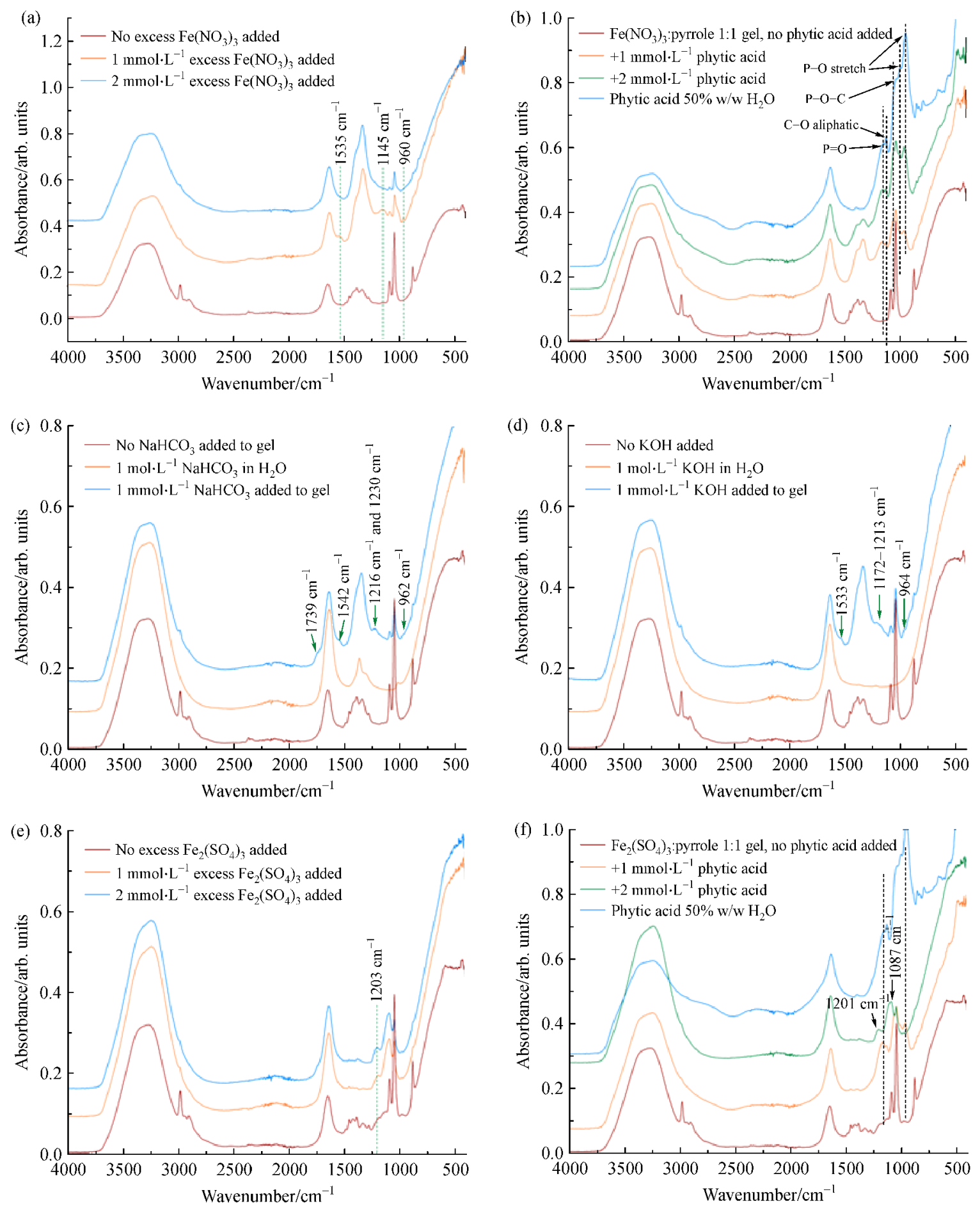

Fig. 3 FTIR spectra of polypyrrole hydrogels. (a) with $\mathrm{Fe}\left(\mathrm{NO}_{3}\right)_{3}$ added, (b) with phytic acid added to hydrogels made with $\mathrm{Fe}\left(\mathrm{NO}_{3}\right)_{3}$, (c) with $\mathrm{NaHCO}_{3}$ added to hydrogels made with $\mathrm{Fe}\left(\mathrm{NO}_{3}\right)_{3}$, (d) with $\mathrm{KOH}$ added to hydrogels made with $\mathrm{Fe}\left(\mathrm{NO}_{3}\right)_{3},(\mathrm{e})$ with $^{\mathrm{Fe}}{ }_{2}\left(\mathrm{SO}_{4}\right)_{3}$ added, (f) with phytic acid added to hydrogels made with $\mathrm{Fe}_{2}\left(\mathrm{SO}_{4}\right)_{3}$

corresponding to the $\left[\mathrm{NO}_{3}\right]^{-}$anion, and a final peak at $1739 \mathrm{~cm}^{-1}$ due to an acyl or alkoxy $\mathrm{C}-\mathrm{O}$ bond from the $\left[\mathrm{CO}_{3}\right]^{2-}$ forming hydrogen bonds with the polypyrrole.

Therefore, results from the FTIR spectra show that hydrogen bonding is indeed present when phytic acid is added to the gels, but addition of alkaline reactants causes ring opening and a potential loss of conductivity, and should thus be avoided. 


\subsection{Electrochemical behaviour}

To test the DC conductivity of the gels, voltages were applied across cubic $1.0 \mathrm{~cm} \times 1.0 \mathrm{~cm}$ samples and the resultant current measured. Therefore, only solid gels could be tested as they could be cut with regular shapes using a scalpel. Uncoated copper foil was placed on opposing sides of the sample-silver paint could not be used as it is immiscible with water, so flat sides were essential to provide accurate contact. The applied voltage was incremented in steps of $0.1 \mathrm{~V}$ up to a maximum of $1 \mathrm{~V}$, with the voltage increased only when the current had reached a steady state.

It can be seen from Fig. 4 that some RC discharging

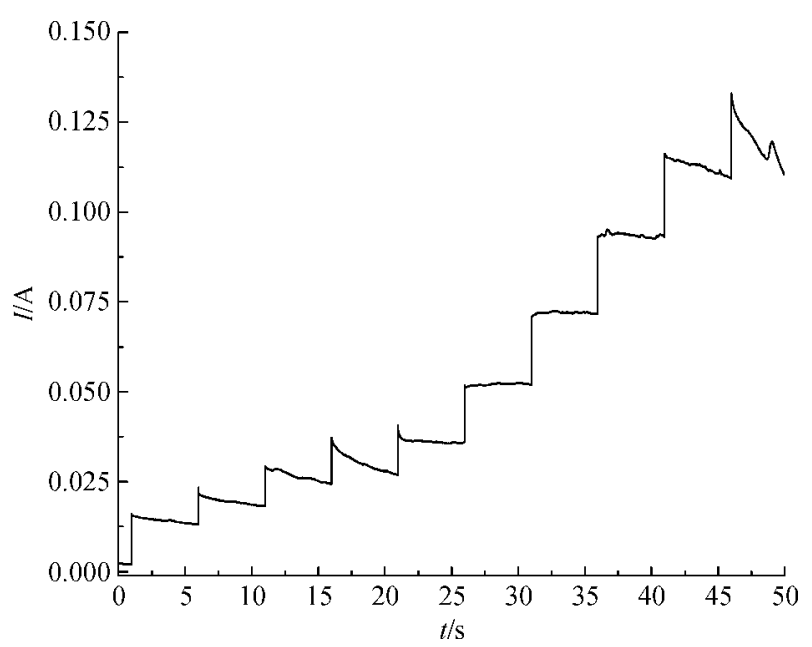

Fig. 4 A representative plot showing the variation of measured current across a sample with an applied stepped voltage (in increments of $0.1 \mathrm{~V}$ every $5 \mathrm{~s}$ )

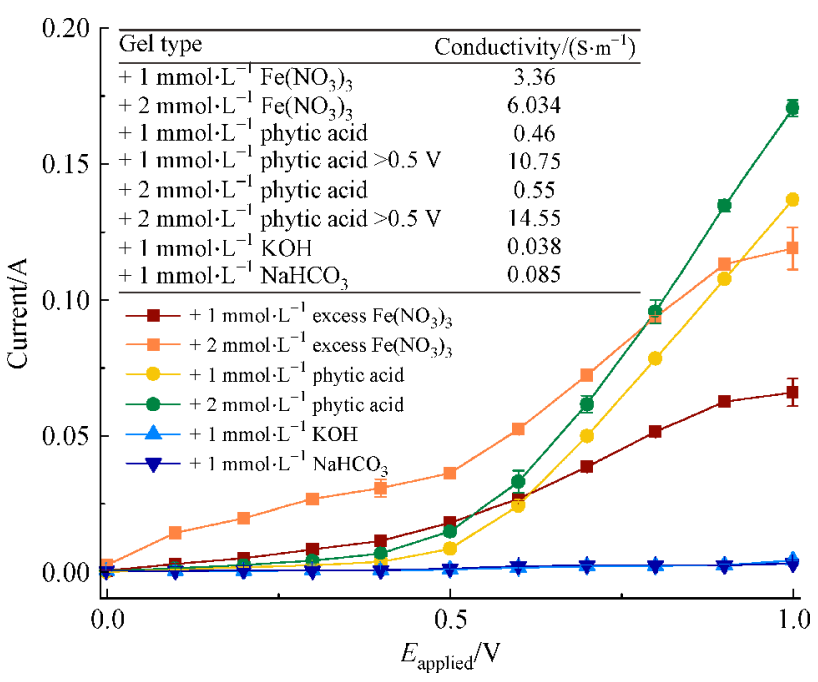

Fig. 5 A plot of the DC conductivity of gels made initially with a 1:1 molar ratio of pyrrole: $\mathrm{Fe}\left(\mathrm{NO}_{3}\right)_{3}$ with respect to applied voltage and molecular addition. Inset: table detailing the conductivities of each gel behaviour occurs (a dropping of current (I) measured with time) - this is unideal if these gels are to be used as supercapacitor electrodes, as it indicates a lack of voltage retention due to short-circuiting through the gel. This is likely due to the increased interconnectivity, as seen by the loss of microstructure in Section 3.1. Comparison of the graphs in Figs. 5 and 6 shows that hydrogels initially made with $\mathrm{Fe}_{2}\left(\mathrm{SO}_{4}\right)_{3}$ had a lower conductivity (as shown in the inset tables), regardless of cross-linking addition. This is likely due to the double charge of the sulphate anion compared to nitrate, which causes increased localised chain deformation and as such increases the bipolaron band gap, i.e., the voltage needed to move the associated bipolaron along the chain. Addition of phytic acid resulted in a two-phase conductivity, with a large increase seen above $0.5 \mathrm{~V}$ applied, in particular in the gels made with $\mathrm{Fe}\left(\mathrm{NO}_{3}\right)_{3}$. This is possibly due to the applied voltage overcoming the hydrogen bonding and causing the phytic acid itself, or its dissociated $\mathrm{H}^{+}$ions, to move. It can be seen that the conductivities after adding alkaline reactants are very low - corroborating with the FTIR spectra which showed ring opening and therefore disruption of the conjugated bonding.

To test the gel's behaviour as a supercapacitor electrode, a custom-made 3-electrode electrochemical cell was used. A $2 \mathrm{~cm}^{2}$ platinum counter electrode and $\mathrm{Ag} / \mathrm{AgCl}$ $0.01 \mathrm{~mol} \cdot \mathrm{L}^{-1}$ reference electrode (Sigma Aldrich) were inserted into the cell alongside a $0.4 \mathrm{~cm}$ diameter cylindrical sample of the hydrogel in contact with a copper current collector, and immersed in an aqueous electrolyte containing $1 \mathrm{~mol} \cdot \mathrm{L}^{-1} \mathrm{H}_{2} \mathrm{SO}_{4}$. To ensure accuracy in the measurements, the hydrogels were immersed in the electrolyte for $4 \mathrm{~h}$ prior to use to ensure full infiltration of the electrolyte into the gel pores. Iviumstat ${ }^{\circledR}$ hardware

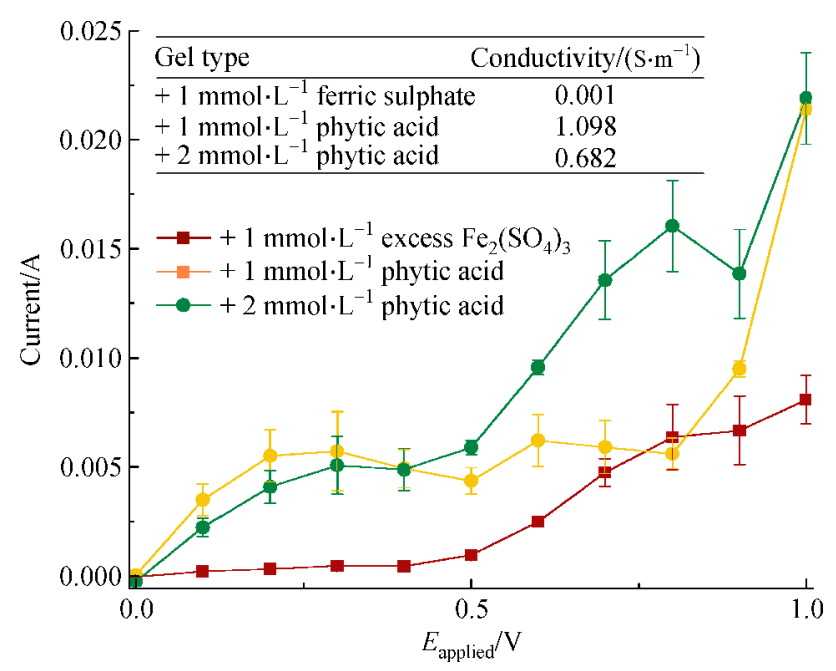

Fig. 6 A plot of the DC conductivity of gels made initially with a 1:1 molar ratio of pyrrole: $\mathrm{Fe}_{2}\left(\mathrm{SO}_{4}\right)_{3}$ with respect to applied voltage and molecular addition. Inset: table detailing the conductivities of each gel 
and software were then used to test the gels' performance in both cyclic voltammetry and electrochemical impedance spectroscopy tests.

Figures 7-9 show the cyclic voltammetry responses of the gels. Addition of phytic acid to the polypyrrole hydrogels initially made with $\mathrm{Fe}\left(\mathrm{NO}_{3}\right)_{3}$ caused the peak corresponding to the reduction of doped to neutral polypyrrole to move from -0.5 to $-0.63 \mathrm{~V}$, whereas the addition of tannic acid increased the peak to $-0.32 \mathrm{~V}$. This movement is likely due to interactions of the phosphate and hydroxyl groups with the $p$-doped polypyrrole, which alter the energy of the bipolarons within the polypyrrole, through electron donation and withdrawal respectively, and thus change the applied voltage at which neutralisation of the polypyrrole occurs. Addition of phytic acid and P106 also show a faint peak at positive applied voltages. This is most likely due to improper washing, resulting in the presence of some remaining $\mathrm{Fe}^{3+}$, which is reduced at an applied potential of $+0.77 \mathrm{~V}$ Standard Hydrogen Electrode (SHE). It can also be seen that addition of phytic acid resulted in a $140 \%$ increase in the specific capacitance of the hydrogel, despite a corresponding loss in accessible surface area, as seen in Section 3.1. This is likely due to additional redox reactions from the phosphate groups providing additional pseudocapacitance, as well as a possible increase in the doping level of the polypyrrole from partial $\left[\mathrm{PO}_{4}\right]^{3-}$ incorporation into the chain [27].

Addition of more $\mathrm{Fe}\left(\mathrm{NO}_{3}\right)_{3}$ to the gels resulted in a smaller hysteresis curve and a higher (more positive) reduction peak. This is likely due to the decrease in accessible surface area and decrease in average molecular weight from more initiation points for secondary polymerisation, which has been shown to affect the reduction voltage of conducting polymers [28]. As expected, addition of $\mathrm{KOH}$ led to a low conductivity and therefore

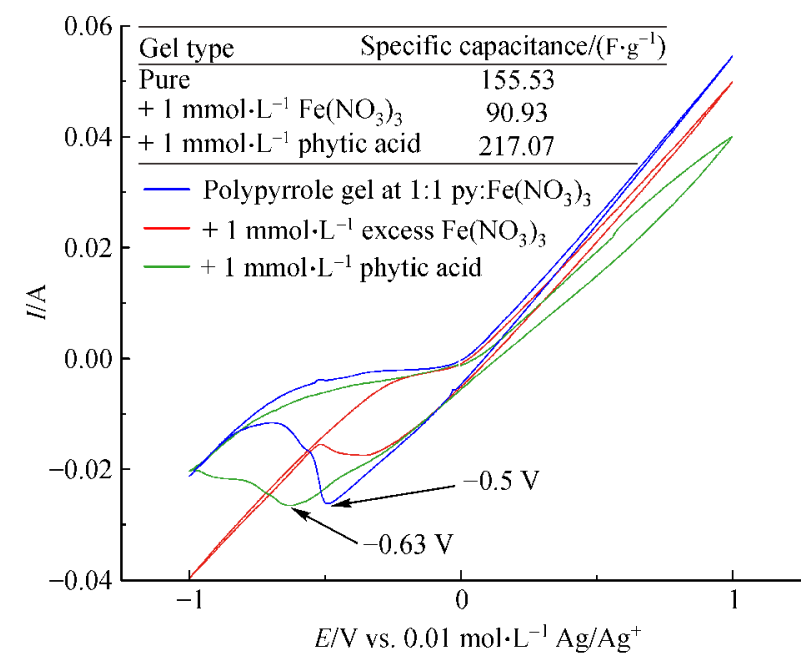

Fig. 7 Cyclic voltammograms showing the hysteretic response of polypyrrole hydrogels, made initially with $\mathrm{Fe}\left(\mathrm{NO}_{3}\right)_{3}$, with $\mathrm{Fe}$ $\left(\mathrm{NO}_{3}\right)_{3}$ and phytic acid added. Scan rate $10 \mathrm{mV} \cdot \mathrm{s}^{-1}$ a decrease in peak anodic current and specific capacitance. Addition of excess ferric nitrate led to an increase in the conductivity (as indicated by a higher value of current, I, at the maximum and minimum applied voltages) but a decrease in the capacitive response due to the loss of surface area and increasing interconnectivity arising from additional secondary polymerisation. Addition of phytic acid to polypyrrole gels made with $\mathrm{Fe}_{2}\left(\mathrm{SO}_{4}\right)_{3}$ led to an improvement in the capacitance of almost $200 \%$, and increased the reduction peak voltage from -0.72 to $-0.57 \mathrm{~V}$. Again this is assumed to be due to the additional pseudocapacitive effect of the phytic acid's phosphate groups, and its incorporation into the polypyrrole leading

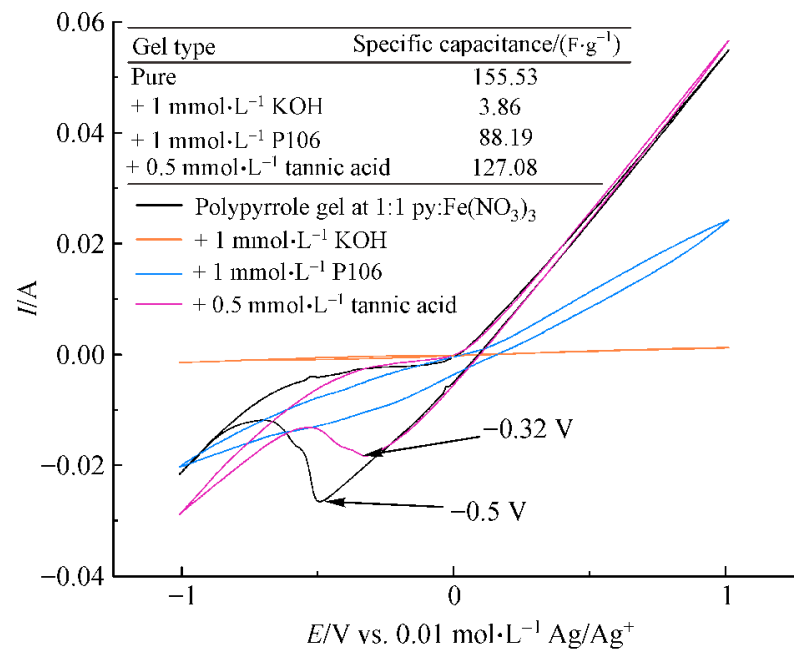

Fig. 8 Cyclic voltammograms showing the hysteretic response of polypyrrole hydrogels, made initially with $\mathrm{Fe}\left(\mathrm{NO}_{3}\right)_{3}$, with tannic acid, $\mathrm{P} 106$, and $\mathrm{KOH}$ added. Scan rate $10 \mathrm{mV} \cdot \mathrm{s}^{-1}$

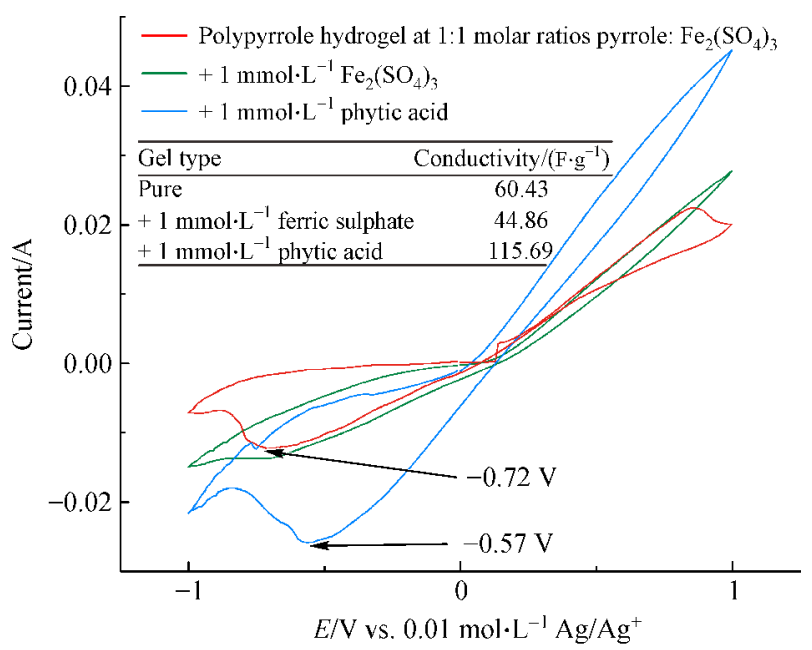

Fig. 9 Cyclic voltammograms showing the hysteretic response of polypyrrole hydrogels made initially with $\mathrm{Fe}_{2}\left(\mathrm{SO}_{4}\right)_{3}$. Scan rate $10 \mathrm{mV} \cdot \mathrm{s}^{-1}$ 
to a more doped polymer. As also seen in the hydrogels made with ferric nitrate, the reduction voltage of fullydoped polypyrrole is around $-0.529 \mathrm{~V}$ at $0.01 \mathrm{~mol} \cdot \mathrm{L}^{-1}$ $\mathrm{Ag} / \mathrm{AgCl}$. Adding excess ferric sulphate led to a loss of reduction peak due to the decrease in surface area accessible to the electrolyte ions.

\subsection{Mechanical properties}

A TA Instruments Discovery HR-3 hybrid rheometer was used to collect information about the viscoelastic properties of the hydrogels. Cylindrical samples of the aged, chemically modified polypyrrole gels with a $10 \mathrm{~mm}$ diameter and a nominal height of $5 \mathrm{~mm}$ were used. Smaller sample thicknesses were unavailable for use due to the fragility of some of the gels. The gel temperature was held at $25^{\circ} \mathrm{C}$ using Peltier plates, with the upper plate of the rheometer lowered until contact with the gel was just made (indicated by a non-zero axial force measurement), to avoid excessive compression of the gels and thus network densification. Plate oscillation, which affects the strain rate experienced by the gel, was gradually increased from $0.1 \mathrm{~Hz}$ to $100 \mathrm{~Hz}$ and shear strain amplitude regulated at $0.01 \%$ to prevent plastic deformation or fracture of the network structure.

Figure 10 shows storage and loss modulus measured at an applied oscillation of $1 \mathrm{~Hz}$ or $6.28 \mathrm{rad} \cdot \mathrm{s}^{-1}$ and a strain of $0.01 \%$. It can be seen from Figs. $10-12$ that for the majority of hydrogels at applied oscillation frequencies of

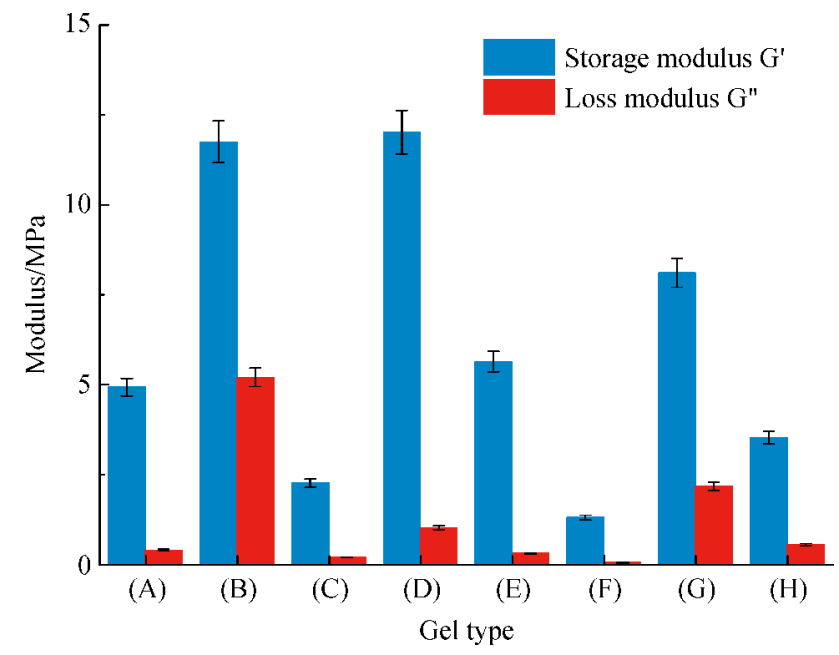

Fig. 10 Bar chart comparing the storage and loss moduli of polypyrrole hydrogels. (a) with $1 \mathrm{mmol} \cdot \mathrm{L}^{-1} \mathrm{Fe}\left(\mathrm{NO}_{3}\right)_{3}$ added to gels initially made with $1: 1$ pyrrole: $\mathrm{Fe}\left(\mathrm{NO}_{3}\right)_{3}$; (b) with $1 \mathrm{mmol}$ $\cdot \mathrm{L}^{-1}$ phytic acid added to these hydrogels; (c) with $2 \mathrm{mmol} \cdot \mathrm{L}^{-1}$ phytic acid added to these hydrogels; (d) with $1 \mathrm{mmol} \cdot \mathrm{L}^{-1} \mathrm{KOH}$ added to these hydrogels; (e) with $1 \mathrm{mmol} \cdot \mathrm{L}^{-1} \mathrm{NaHCO}_{3}$ added to these hydrogels; (f) with $1 \mathrm{mmol} \cdot \mathrm{L}^{-1} \mathrm{Fe}_{2}\left(\mathrm{SO}_{4}\right)_{3}$ added to gels initially made with $1: 1$ pyrrole: $\mathrm{Fe}_{2}\left(\mathrm{SO}_{4}\right)_{3}$; $(\mathrm{g})$ with $1 \mathrm{mmol} \cdot \mathrm{L}^{-1}$ phytic acid added to these hydrogels; (h) with $2 \mathrm{mmol} \cdot \mathrm{L}^{-1}$ phytic acid added to these hydrogels
$1 \mathrm{~Hz}$, the storage modulus $\mathrm{G}^{\prime}$ was greater than the loss modulus G", indicating that the gels exhibit more elastic (rather than viscous) behaviour. This is ideal for the gels' use in a supercapacitor electrode as it means that creep is minimised, and so helps enable a structurally-stable device. The plots also demonstrate how the stiffness of the gels depends heavily on the post-gelation additions of cross-linking molecules, and that although making gels with ferric sulphate normally creates less-stiff gels than those made with ferric nitrate (due to difference in initial ferric ion number density leading to a difference in polymerisation initiation sites and eventual polypyrrole sphere size, and a lower molecular weight distribution after ageing), addition of phytic acid can change this.

One of the most dramatic changes in moduli was seen with an addition of $1 \mathrm{mmol} \cdot \mathrm{L}^{-1}$ phytic acid to gels made with ferric sulphate: an increase in the shear storage modulus of $620 \%$ and a corresponding increase in shear loss modulus by a factor of $106 \%$ were observed in comparison to the pristine hydrogel. This indicated an increase in the stiffness of the gels but also an increased softness. This is likely due to the effect of the phytic acid's hydrogen bonding: increased hydrogen bond cross-links between the polypyrrole chains lead to an increase in stiffness, but the presence of phytic acid also increases the hydrogel's hydrophilicity, leading to increased water content within the gel. This can explain the drop in stiffness observed when $2 \mathrm{mmol} \cdot \mathrm{L}^{-1}$ of phytic acid was added, as opposed to $1 \mathrm{mmol} \cdot \mathrm{L}^{-1}$. Additionally, use of potassium hydroxide to alter the polypyrrole hydrogel structure resulted in an extremely stiff, but brittle gel. This likely occurs due to some pore collapse and densification of the structure in comparison to the other gels, which were reinforced through molecular additions and an increase in chemical cross-link density, as can be seen in the SEM images of Figure 1. This is corroborated by the $\mathrm{KOH}-\mathrm{NO}_{3}$ gel's very low ratio of loss modulus:storage modulus of 0.085 , indicating more glassy behaviour of the gel, which would occur in a denser but less cross-linked gel.

Cross-over of the $\mathrm{G}^{\prime}$ and $\mathrm{G}^{\prime \prime}$ curves were projected to occur (using Trios software provided by T.A. Instruments) at frequencies of between 5 and $14 \mathrm{~Hz}$ (between a shear strain rate of 5.7 and $20 \mathrm{~s}^{-1}$ ), as seen in Figs. 11 and 12, and the point occurred at a higher strain rate for the gels with a higher storage modulus. The crossover point indicates a change from gel-like to liquid-like behaviour, and in this case is likely due to expulsion of water from the pores and its inability to re-integrate and swell the pores at high strain rates. Stiffer gels exhibit less pore collapse and therefore less water expulsion. Some sliding of the samples between the plates was also observed which led to inaccurate measurements, in particular when a higher strain of $0.1 \%$ used which led to greater plate oscillation amplitude. This could be resolved by increasing the downwards force applied by the plate to the sample, but this led to pore densification and inaccurate measurements. 


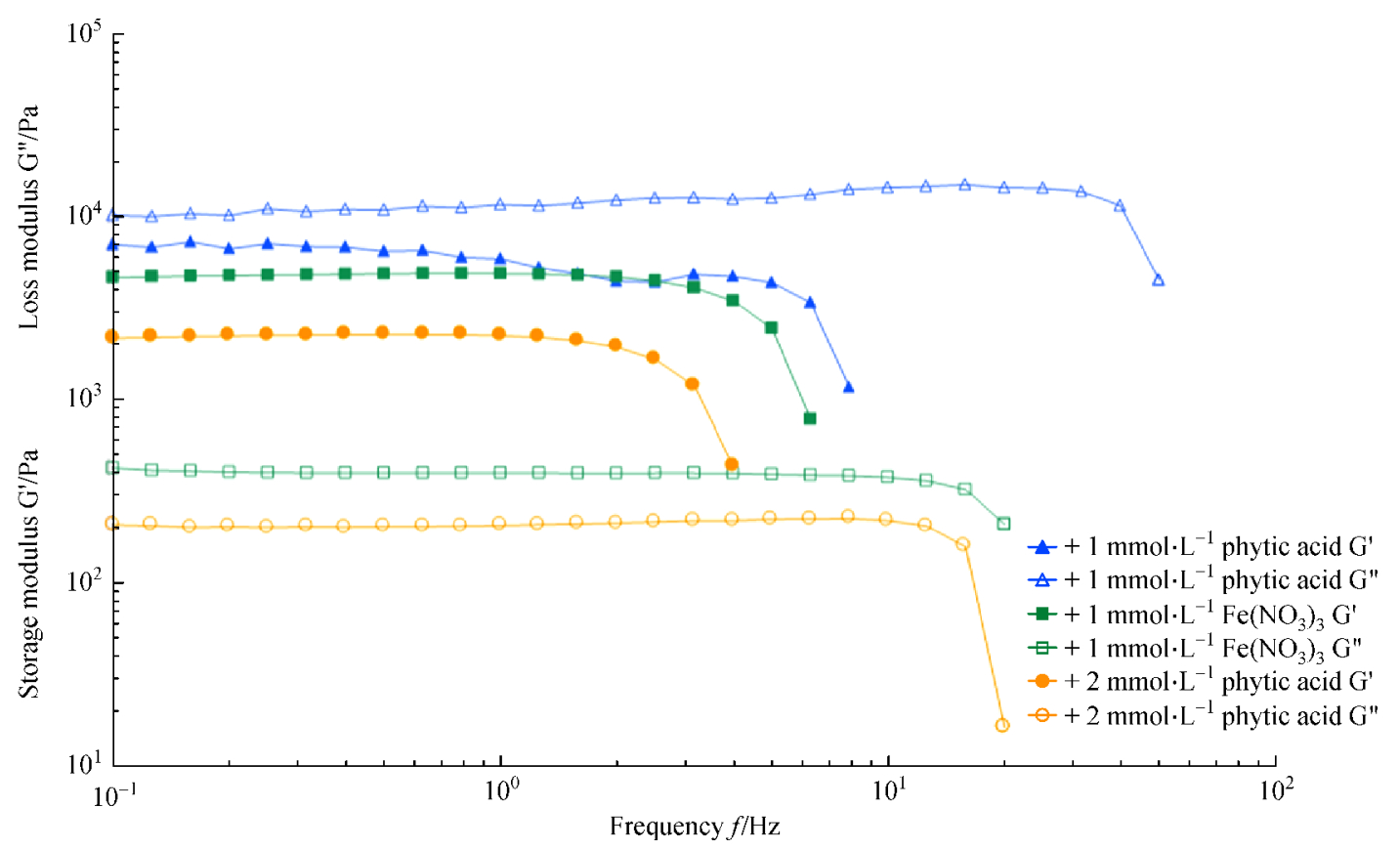

Fig. 11 Plots of the storage $\left(G^{\prime}\right)$ and loss $\left(G^{\prime \prime}\right)$ moduli with increasing applied rotational frequency of polypyrrole hydrogels initially made with 1:1 molar ratio of pyrrole: $\mathrm{Fe}\left(\mathrm{NO}_{3}\right)_{3}$

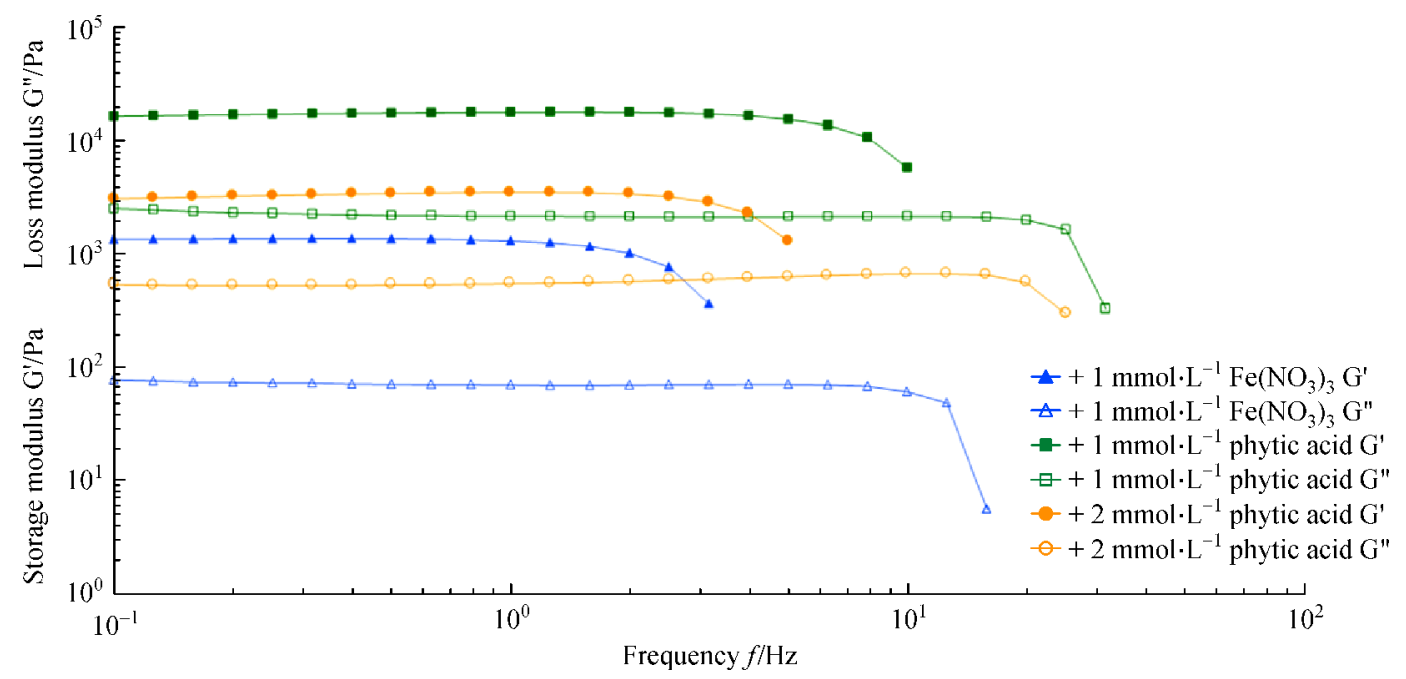

Fig. 12 Plots of the storage $\left(G^{\prime}\right)$ and loss $\left(G^{\prime \prime}\right)$ moduli with increasing applied rotational frequency of polypyrrole hydrogels initially made with 1:1 molar ratio of pyrrole: $\mathrm{Fe}_{2}\left(\mathrm{SO}_{4}\right)_{3}$

\section{Conclusions}

Polypyrrole hydrogels with a controllable degree of porosity were created from just two reactants, pyrrole and a ferric salt which acted as simultaneous oxidant and dopant; both in aqueous solutions. Use of stoichiometrically deficient ratios of ferric salt led to a secondary ageing process whereby lower-molecular weight polypyrrole chains were produced and grown as cross-links within the interconnected sphere network of the gel. This leads to an increase in elasticity and tensile strength due to increased network interconnectivity. Additional reactants were added post-polymerisation, but pre-gelation, to further cross-link the network to increase both stiffness and strength.

Adding excess ferric salt leads to destruction of the highsurface area microstructure and a loss of charge storage ability, with no additional redox-active molecules added to increase the capacitance. However, the elasticity of the hydrogel is retained, and a small increase in stiffness is observed. Addition of phytic acid increased the specific capacitance of the hydrogels through the presence of 
additional redox reactions and increased doping of polypyrrole, although it did also lead to a decrease in surface area. Adding of phytic acid to hydrogels made with ferric sulphate in particular led to a large increase in the gels' stiffness, and a $140 \%$ improvement in capacitance. This may be due to the additional redox activity of the phytic acid's phosphate groups - as a shift in reduction peak of $+0.25 \mathrm{~V}$ was also seen - and improved hydrogen bonding leading to an increased cross-link density. However, adding a greater proportion of phytic acid to the polypyrrole hydrogels also caused increased swelling of the hydrogel networks due to the gels' increased hydrophilicity (from the hydroxyl groups of the phytic acid) and as such, addition of 2 milliMoles of phytic acid: 1 Mole pyrrole led to softer gels than addition of 1 milliMole.

Other hydrogen bonding molecules would prove a useful investigation, as well as other types of bonding, for example amide cross-linking with pyrrole-3-carboxylic acids and diamine molecules. Similar to incorporation of $\mathrm{CuTcPs}$, adding additional $\left[\mathrm{SO}_{4}\right]^{2-}$ ions without additional $\mathrm{Fe}^{3+}$ cations might help to improve the stiffness, without the loss of surface area through initiation of secondary polymerisation as seen in this paper. Successful use of anionic cross-links this small has not yet been demonstrated [22].

Acknowledgements This work was made possible by funding provided by the Engineering and Physical Sciences Research Council (EPSRC), funding number "EP/N509565/1".

Open Access This article is licensed under a Creative Commons Attribution 4.0 International License, which permits use, sharing, adaptation, distribution and reproduction in any medium or format, as long as you give appropriate credit to the original author(s) and the source, provide a link to the Creative Commons licence, and indicate if changes were made. The images or other third party material in this article are included in the article's Creative Commons licence, unless indicated otherwise in a credit line to the material. If material is not included in the article's Creative Commons licence and your intended use is not permitted by statutory regulation or exceeds the permitted use, you will need to obtain permission directly from the copyright holder. To view a copy of this licence, visit http://creativecommons.org/licenses/by/4.0/.

\section{References}

1. González A, Goikolea E, Barrena J A, Mysyk R. Review on supercapacitors: Technologies and material. Renewable \& Sustainable Energy Reviews, 2016, 58: 1189-1206

2. Shown I, Ganguly A, Chen L C, Chen K H. Conducting polymerbased flexible supercapacitor. Energy Science \& Engineering, 2015, 3(1): 2-26

3. Wang G, Zhang L, Zhang J. A review of electrode materials for electrochemical supercapacitors. Chemical Society Reviews, 2012, 41(2): 797-828

4. Shi Y, Yu G. Designing hierarchically nanostructured conductive polymer gels for electrochemical energy storage and conversion.
Chemistry of Materials, 2016, 28(8): 2466-2477

5. Stejskal J, Trchovä M, Bober $\mathrm{P}$, Moràvkovà Z, Kopecký D, Vrňata M, Prokeš J, Varga M, Watzlovà E. Polypyrrole salts and bases: Superior conductivity of nanotubes and their stability towards the loss of conductivity by deprotonation. RSC Advances, 2016, 6(91): 88382-88391

6. Zhang X, Zhang J, Song W, Lu Z. Controllable synthesis of conducting polypyrrole nanostructures. Journal of Physical Chemistry B, 2006, 110(3): 1158-1165

7. Kaynak A. Electrical conductivity of polypyrrole films at a temperature range of $70 \mathrm{~K}$ to $350 \mathrm{~K}$. Materials Research Bulletin, 1998, 33(1): 81-88

8. Brédas J L, Thémans B, André J M. Bipolarons in polypyrrole chains. Physical Review. B, 1983, 27(12): 7827-7830

9. Otaigbe J U. The processing, structure and properties of elastomeric fibres. Handbook of Textile Fibre Structure. Volume 1: Fundamentals and Manufactured Polymer Fibres. Cambridge: Elsevier, Woodhead Publishing, 2009, 1-528

10. Tan Y, Ghandi K. Kinetics and mechanism of pyrrole chemical polymerization. Synthetic Metals, 2013, 175: 183-191

11. Kang H, Geckeler K. Enhanced electrical conductivity of polypyrrole prepared by chemical oxidative polymerization: Effect of the preparation technique and polymer additive. Polymer, 2000, 41(18): 6931-6934

12. Pan L, Chortos A, Yu G, Wang Y, Isaacson S, Allen R, Shi Y, Dauskardt R, Bao Z. An ultra-sensitive resistive pressure sensor based on hollow-sphere microstructure induced elasticity in conducting polymer film. Nature Communications, 2014, 5(1): 1-8

13. Shi Y, Pan L, Liu B, Wang Y, Cui Y, Bao Z, Yu G. Nanostructured conductive polypyrrole hydrogels as high-performance, flexible supercapacitor electrodes. Journal of Materials Chemistry. A, Materials for Energy and Sustainability, 2014, 2(17): 6086-6091

14. Rajesh M, Raj J C, Kim B C, Cho B B, Ko M, Yu K H. Supercapacitive studies on electropolymerized natural organic phosphate doped polypyrrole thin films. Electrochimica Acta, 2016, 220: 373-383

15. Zhou H, Ni T, Qing X, Yue X, Li G, Lu Y. One-step construction of graphene-polypyrrole hydrogels and their superior electrochemical performance. RSC Advances, 2013, 4(8): 4134-4139

16. Bai H, Sheng K, Zhang P, Li C, Shi G. Graphene oxide/conducting polymer composite hydrogels. Journal of Materials Chemistry, 2011, 21(46): 18653-18658

17. Lu Y, He W, Cao T, Guo H, Zhang Y, Li Q, Shao Z, Cui Y, Zhang $\mathrm{X}$. Elastic, conductive, polymeric hydrogels and sponges. Scientific Reports, 2014, 4: 1-8

18. Zhou X, Li T, Wang J, Chen F, Zhou D, Liu Q, Zhang L, Shena J, Zhou X. Shape morphing of anisotropy-encoded tough hydrogels enabled by asymmetrically-induced swelling and site-specific mechanical strengthening. Journal of Materials Chemistry. B, Materials for Biology and Medicine, 2018, 29(29): 4731-4737

19. Zhou X, Li T, Wang J, Chen F, Zhou D, Liu Q, Li B, Cheng J, Zhou $\mathrm{X}$, Zheng B. Mechanochemical regulated origami with tough hydrogels by ion transfer printing. ACS Applied Materials \& Interfaces, 2018, 10(10): 9077-9084

20. Li T, Wang J, Zhang L, Yang J, Yang M, Zhu D, Zhou X, Handschuh-Wang S, Liua Y, Zhou X. "Freezing", morphing, and 
folding of stretchy tough hydrogels. Journal of Materials Chemistry. B, Materials for Biology and Medicine, 2017, 29(29): 5726-5732

21. Dai T, Qing X, Zhou H, Shen C, Wang J, Lu Y. Mechanically strong conducting hydrogels with special double network structure. Synthetic Metals, 2010, 160(7-8): 791-796

22. Bredas J L, Scott J C, Yakushi K, Street G B. Polarons and bipolarons in polypyrrole: Evolution of the band structure and optical spectrum upon doping. Physical Review. B, 1984, 30(2): 1023-1025

23. Wang Y, Shi Y, Pan L, Ding Y, Zhao Y, Li Y, Shi Y, Yu G. Dopantenabled supramolecular approach for controlled synthesis of nanostructured conductive polymer hydrogels. Nano Letters, 2015, 15(11): 7736-7741

24. Ghosh S, Inganäs O. Conducting polymer hydrogels as $3 \mathrm{D}$ electrodes: Applications for supercapacitors. Advanced Materials, 1999, 11(14): 1214-1218
25. Neoh K G, Young T T, Kang E T, Tan K L. Structural and mechanical degradation of polypyrrole films due to aqueous media and heat treatment and the subsequent redoping characteristics. Journal of Applied Polymer Science, 1997, 64(3): 519-526

26. Xie Q, Kuwabata S, Yoneyama H. EQCM studies on polypyrrole in aqueous solutions. Journal of Electroanalytical Chemistry, 1997, 420(1-2): 219-225

27. MacDiarmid A G, Mammone R J, Kaner R B, Porter S J, Pethig R, Heeger A J, Rosseinsky D R. The concept of 'doping' of conducting polymers: The role of reduction potentials. Philosophical Transactions of the Royal Society A: Mathematical, Physical and Engineering Sciences, 1985, 314(1528): 3-15

28. Diaz A, Crowley J, Bargon J, Gardini G, Torrance J. Electrooxidation of aromatic oligomers and conducting polymers. Journal of Electroanalytical Chemistry and Interfacial Electrochemistry, 1981, 121: 355-361 